\title{
PKM Penyuluhan Permainan Matematika Bagi Para Guru di SDN Cibitung Kulon 01 Pagi
}

\author{
Chrisnaji Banindra Yudha1*, Eva Oktaviana ${ }^{2}$, Evi Faujiah ${ }^{3}$ \\ 1,2,3STKIP Kusuma Negara, Jakarta, Indonesia \\ *Corresponding Author: chrisnaji_by@stkipkusumanegara.ac.id
}

\begin{abstract}
Info Artikel Diterima : 03/03/2021
Direvisi: 01/05/2021

Disetujui: 21/05/2021

Abstract. At SD Negeri Cibitung Kulon 01 Pagi the teacher still plays a role as a learning center so that students are less actively involved during learning. This condition makes mathematics learning less attractive in the eyes of students and as a result students are less enthusiastic during the learning process, so that the purpose of holding community service activities is to increase the understanding and ability of teachers of SDN Cibitung Kulon 01 Pagi about fun mathematics learning, while the method used is education in community in the form of socialization activities to increase participants' knowledge / understanding of how to create fun mathematics learning in class. with puzzle tetris math games. The results of the evaluation on the implementation of this PKM were obtained from the number of participants who attended as many as 15 people, 8 teachers understood the material very well or were in the high category, while 5 teachers understood maeri well and only 2 teachers did not understand the material that had been explained. The results of this evaluation are a benchmark that the PKM goals are achieved. The evaluation that has been given to the teacher is in the form of an essay question as many as 25 questions related to the material that has been delivered. The conclusion that can be obtained from the implementation of this community service program is: this socialization activity can increase teachers' knowledge about how to create fun mathematics learning in the classroom. Furthermore, the implementation of this community service activity program has been running smoothly and as expected, both by members of the extension team and community service program participants.Abstract written in English which contains a brief description of the background and objectives, methods of implementation, results and discussion, conclusions and recommendation for follow-up.
\end{abstract}

Keywords: PKM, Played, Fun Math, Tetris Math

\begin{abstract}
Abstrak. Di sekolah SD Negeri Cibitung Kulon 01 Pagi Guru masih berperan sebagai pusat pembelajaran sehingga siswa kurang terlibat secara aktif selama pembelajaran. Kondisi ini menjadikan pembelajaran matematika kurang menarik di mata siswa dan akibatnya siswa kurang bersemangat selama proses pembelajaran, sehingga tujuan diselenggarakannya kegiatan pengabdian adalah meningkatkan pemahaman dan kemampuan guru-guru SDN Cibitung Kulon 01 Pagi tentang pembelajaran matematika yang menyenangkan, adapun metode yang digunakan yaitu pendidikan pada masyarakat berupa kegiatan sosialisasi untuk meningkatkan pengetahuan/pemahaman peserta mengenai cara menciptakan pembelajaran matematika yang menyenangkan di kelas melalui penerapan games puzzle tetris math. Hasil evaluasi pada pelaksanaan PKM ini didaptkan dari jumlah peserta yang hadir sebanyak 15 orang, 8 orang guru memhami materi dengan sangat baik atau dalam kategori tinggi, sedangkan 5 orang guru memahami maeri dengan baik dan hanya 2 orang guru yang kurang memahami materi yang telah dijelaskan. Hasil evalusai ini menjadi tolak ukur bahwa tujuan PKM tercapai. Evaluasi yang telah diberikan kepada guru berbentuk soal uataian sebanyak 25 soal terkait materi yang telah disampaikan. Kesimpulan yang dapat diperoleh dari pelaksanaan program pengabdian kepada masyarakat ini adalah: kegiatan sosialisasi ini dapat meningkatkan pengetahuan guru- guru mengenai cara menciptakan pembelajaran matematika yang menyenangkan di kelas. Selanjutnya, pelaksanaan dari program kegiatan pengabdian pada masyarakat ini sudah berjalan dengan lancar dan sesuai dengan yang diharapkan, baik oleh anggota tim penyuluhan maupun para peserta program pengabdian masyarakat.
\end{abstract}

Kata Kunci: Bermain, Matematika yang menyenangkan, Tetris Matematika

How to Cite: Yudha, C.B., Oktaviana, E. \& Faujiah, E. (2021). PKM Penyuluhan Permainan Matematika Bagi Para Guru di SDN Cibitung Kulon 01 Pagi. Prima Abdika: Jurnal Pengabdian Masyarakat, 1(2), 42-51. https://doi.org/10.37478/abdika.v1i2.940

Copyright (c) 2021 Chrisnaji Banindra Yudha, Eva Oktaviana, Evi Faujiah. This work is licensed under a Creative Commons Attribution-ShareAlike 4.0 International License.

\section{Pendahuluan}

Sebagian besar siswa masih menganggap matematika merupakan mata pelajaran yang sulit dan tidak menyenangkan untuk dipelajari, sehingga muncul istilah "mathematics is monster". Anggapan yang melekat pada siswa tersebut berdampak negatif pada proses dan hasil pembelajaran 
siswa. Berdasarkan hasil pengamatan dan informasi yang diperoleh, pembelajaran matematika di kelas masih menggunakan metode konvensional. Sedangkan mata pelajaran matematika memiliki peran penting dalam berbagai bidang ilmu, karena ilmu matematika diterapkan pada kehidupan sehari-hari. Sedemikian pentingnya hingga matematika perlu dibekali kepada siswa mulai dari jenjang sekolah dasar agar memiliki kemampuan berpikir logis, sistematis, kritis, serta mampu bekerja sama dalam lingkungan (Yudha \& Suwarjo, 2014).

Dalam pendidikan, proses belajar dan mengajar adalah fenomena yang kompleks. Segala sesuatu yang terjadi pada rancangan dan proses pengajaran sejauh itu pula proses belajar berlangsung. Pembelajaran dapat tercapai dengan baik apabila pada proses belajar mengajar yang terjadi melibatkan siswa secara aktif sehingga dapat melahirkan pembelajaran yang menyenangkan, hal ini tentu tidak luput dari baiknya kualitas kompetensi guru yang diperlukan saat mengajar. Dalam hal ini pengaruh dari peran seorang pendidik sangat besar sekali.

Guru harus dapat memilih metode pembelajaran yang tepat digunakan sesuai dengan karakteristik siswa untuk menunjang pembelajaran agar tujuan pembelajaran yang telah ditetapkan dapat tercapai dengan baik, dan pengembangan media ajar tentu diperlukan agar siswa dapat terhindar dari pembelajaran yang membosankan dan tidak menyenangkan yang akan berdampak pada hasil belajar mereka, untuk itu guru profesional harus mampu berpikir kreatif dan inovatif dalam menjalankan tugasnya.

Kurikulum 2013 yang menjadi landasan pendidikan Indonesia saat ini menuntut dilaksanakannya pembelajaran yang partisipatif, aktif, inovatif, kreatif, dan menyenangkan (PAIKEM). Kurikulum 2013 menganut pandangan dasar bahwa pengetahuan tidak dapat dipindahkan begitu saja dari guru ke siswa, melainkan siswa adalah subyek yang memiliki kemampuan aktif mencari, mengolah, mengkonstruksi, dan menggunakan pengetahuan. Pembelajaran harus berkenaan dengan kesempatan yang diberikan kepada siswa untuk mengkonstruksi pengetahuannya.

Matematika sebagai salah satu mata pelajaran yang wajib diberikan kepada siswa pun memerlukan metode pembelajaran yang tepat agar pembelajaran dapat berlangsung secara efektif, efisien dan menyenangkan sesuai dengan prosedur Kurikulum 2013. metode pembelajaran yang lebih tepat bagi siswanya, tentu disertai dengan penyesuaian gaya mengajar pendidik dengan gaya belajar siswa, apabila hal ini tidak dilakukan maka akan mengakibatkan proses belajar mengajar matematika tidak optimal, maka dari itu seorang instruktur perlu memperhatikan metode yang efektif dan gaya mengajar yang tepat sesuai dengan kebutuhan dan karakteristik siswa disertai dengan materi yang akan diajarkan.

Mengingat adanya perbedaan karakteristik dalam materi matematika maka diperlukan kompetensi seorang guru untuk menjembatani antara dunia anak yang belum berpikir secara kritis agar dapat mengerti dunia matematika yang merupakan ilmu pasti. Namun masih banyak didapati pada proses pembelajaran matematika siswa kesulitan dalam memahami materi dan tidak bergairah dalam pembelajaran karena guru masih menggunakan metode yang sama berulang-ulang dan tidak ada penyediaan media yang menarik sehingga pembelajaran menjadi pasif dan tidak efektif, 
hal ini juga merupakan faktor dari karakteristik anak yang masih berada pada tahap operasional konkret sehingga perlu belajar dengan pembelajaran yang menarik minat anak.

Nanang Priatna dan Ricki Yuliardi (2018) berpendapat bahwa matematika sebagai ilmu yang bersifat deduktif, logis, aksiomatik, simbolik, hierarkis-matematis dan abstrak. Maka dari kedua pendpaat tokoh dapat disimpulkan matematika adalah ilmu yang bersifat deduktif, logis, aksiomatik, simbolik, hierarkis-matematis dan abstrak, yang sangat penting dipelajari oleh siswa untuk melatih pola pikir, diantaranya berpikir logis, analitis, dan kritis, kemampuan pola pikir akan dimiliki oleh seorang siswa apabila pembelajaran matematika di sekolah disajikan secara kreatif dan sistematis.

Permasalahan yang terjadi adalah tingkat keaktifan siswa srendah. Hal ini, dapat dilihat pada saat guru memberikan kesempatan siswa untuk tampil di depan kelas menuliskan, mempresentasikan, atau menempelkan hasil jawaban siswa enggan, siswa tidak mau aktif di kelas karena siswa merasa malu dan selalu dihantui rasa cemas karena takut salah dalam mengerjakan soal matematika. Selain itu, pada setiap sesi pertanyaan yang dilakukan oleh guru pada materi yang belum jelas, semua siswa malu bertanya padahal mereka belum memahami materi. Menurut pengakuan salah satu siswa, hal tersebut karena siswa merasa takut pada saat mengikuti pelajaran matematika karena sudah tertanam pada pemikiran siswa bahwa matematika adalah pelajaran yang sulit untuk dipahami dan dikerjakan. Pengakuan tersebut juga dialami oleh siswa lain.

Proses pembelajaran yang dilakukan oleh guru kelas pada saat itu hanya menggunakan metode ceramah pada materi bangun datar dan tidak disertai dengan penggunaan media yang memadai sehingga pembelajaran berjalan kurang maksimal dan pasif. Pada proses menjelaskan materipun penjelasan berlangsung sangat singkat dan kurang dilakukan secara detail, kemudian pembelajaran langsung dilanjutkan dengan pemberian tugas sehingga awal-awal siswa banyak yang terlihat bingung untuk mengerjakan tugasnya dan sebagian besar merasa bosan dan tidak bersemangat saat pembelajaran berlangsung. Tak mengherankan hal ini terjadi karena tahapan usia mereka masih pada tahap operasional konkret.

Secara umum pada saat observasi, siswa mampu mengikuti pembelajaran matematika pada materi bangun datar dengan baik meskipun kurang maksimal. Kreativitas yang minim seorang guru saat menyampaikan pembelajaran matematika menjadi alasan pembelajaran yang berlangsung tidak bergairah dan cenderung pasif, hal ini terbukti dari hasil wawancara oleh guru tersebut di mana fasilitas sekolah tidak mendukung guru untuk melakukan pembelajaran yang kreatif dan inovatif, sehingga guru tidak pernah melakukan pengembangan pembelajaran yang inovatif sebelumnya dan guru hanya bertumpu pada gaya mengajar tradisional yang monoton.

Berdasarkan hasil wawancara peneliti dengan guru, terungkap bahwa guru lebih sulit memberikan pemahaman konsep matematika dari pada mata pelajaran yang lain. Guru hanya menyampaikan rumus dan siswa mencatat rumus tersebut tanpa deberikan penjelasan, peragaan, langkah atau asal mula mendapatkan rumus tersebut. Hal ini sangat menghambat transfer pembelajaran khususnya mata pelajaran matematika. Hal ini 
menyebabkan siswa hanya dapat memahami pelajaran tanpa mengetahui implementasi dalam kehidupan sehari-hari. Dengan demikian siswa di SD tersebut membutuhkan beberapa kegiatan untuk menumbuhkan keaktifan dalam pembelajaran matematika, salah satunya penerapan games tetris math.

Permainan tetris dibuat pertama kali oleh seorang Ilmuwan Uni Soviet bernama Alexey Pajitnov pada tahun 1984 di laboratorium Soviet Academy of Sciences. Waktu itu permainan ini belum bernama tetris, namanya adalah Tetrominoes. Pajitnov membuatnya menggunakan sebuah komputer kuno, yaitu komputer pertama di zaman itu. Tetris adalah teka-teki yang didesain dan diprogram oleh Alexey Pajitnov pada bulan Juni 1985, pada saat ia bekerja di Pusat Komputer Dorodnicyn di Akademi Sains Uni Soviet di Moskow. Namanya berasal dari awalan numerik Yunani tetra yang bermakna bangun dengan empat bagian. Setiap 7 variasi blok tetromino memiliki nama masing-masing: O-Tetromino, I-Tetromino, T-Tetromino, LTetromino, J-Tetromino, S-Tetromino, dan Z-Tetromino (Kemdikbud 2018).

Permainan tetris mengggunakan kepingan berbentuk balok di mana masing-masing kepingan tersebut dapat diputar hingga $90^{\circ}$ berlawanan dengan arah jarum jam untuk memenuhi kepingan lain. Putaran yang cukup akan mengembalikan kepingan tersebut pada posisi semula/aslinya, masing-masing kepingan memiliki diantara 2 dan putaran yang berbeda, hal ini menurut Nick (2011). Kepingan persegi memiliki satu putaran, Kepingan $Z$ memiliki 2 arah putaran, dan kepingan berebntuk L memiliki 4 putaran. Dari permainan tetris tersebut oleh penelitian yang dilaksanakan oleh Risma Ratu dkk Pada tahun 2020 dibuat dengan pepaduan dengan puzzle, sehingga disebut permainannya adalah puzzle tetris matematika.

Kata "Puzzle" menurut Ahmad dan Amini memiliki arti dari sebuah permainan yang dapat mengasah kemampuan anak dalam memecahkan beragam masalah dengan menggunakan logika dan dapat mengembangkan kemampuan logika matematika, hal ini disampaikan oleh Ahmad dan Amini (2020).

Puzzle diartikan sebagai tebakan atau bongkar pasang, dalam tebakan atau bongkar pasang terdapat masalah yang diberikan sebagai hiburan. Media puzzle merupakan media pembelajaran yang menggunakan unsur permainan dan penggunaan gambar sederhana. Penggunaan media puzzle dalam pembelajaran tentunya akan lebih menarik minat siswa dalam belajar, selain itu dengan menggunakan media puzzle siswa diajak untuk berpikir kritis untuk memecahkan teka-teki dari puzzle itu sendiri", pendapat ini disampaikan oleh wiwi dkk (2019).

Alat permainan adalah semua alat yang digunakan anak untuk memenuhi naluri bermainnya, sedangkan alat permainan edukatif adalah alat permainan yang sengaja dirancang secara khusus untuk kepentingan pendidikan. Tujuan bermain ialah untuk memelihara perkembangan dan pertumbuhan optimal anak melalui pendekatan bermain yang kreatif, interaktif, dan terintegrasi dengan lingkungan bermain anak. Media puzzle adalah media permainan anak yang menarik dan menyenangkan akan meningkatkan kemampuan kogntif anak.

Dienes memandang matematika sebagai pelajaran struktur, klasifikasi struktur, relasi-relasi dalam struktur, dan mengklasifikasikan relasi-relasi 
antara struktur. Ia percaya bahwa setiap konsep matematika akan dapat dipahami dengan baik oleh siswa apabila disajikan dalam bentuk konkret dan beragam (Karso, Dkk 2014). Untuk itu penggunaan media yang beragam serta permainan sangat tepat digunakan bagi siswa SD karena usia anak pada saat itu tidak dapat dipisahkan dengan bermain. Anak-anak usia SD masih senang bermain jika permainan diterapkan pada pembelajaran Matematika dapat mendorong pembelajaran yang berhasil. Benda-benda atau obyek-obyek dalam bentuk permainan akan sangat berperan bila dimanipulasi dengan baik dalam pengajaran matematika, hal ini disampaikan oleh Atiaturrahmaniah, dkk (2017).

Manfaat permainan menurut Rifa (2012) bagi anak-anak diantaranya adalah : (1) memunculkan dorongan pada anak untuk mencoba hal baru, (2) mengembangkan aspek sosial karena anak melakukan interaksi dengan yang lain selama permainan dan bisa mempererat hubungan antar anak, (3) menumbuhkan dan mengembangkan imajinasi anak, serta dapat mempertajam kemampuan berfikir, (4) meningkatkan kemampuan refleks, motorik halus dan memperkaya penguasaan kosakata, dan (5) melatih konsentrasi, (6) meningkatkan percaya diri.

Setelah siswa mempelajari konsep dan struktur matematika terkait, mereka harus memilih beberapa sifat dasarnya, mengaturnya, dan mempertimbangkan konsekuensinya. Siswa sudah dapat membuktikan temuannya dan memecahkan masalah yang dihadapinya tentang materi yang Ia pelajari. Pada tahap ini, siswa memeriksa konsekuensi konsep untuk memecahkan masalah matematika murni dan terapan.

Dari beberapa penelitian yang telah dilaksanakan, Farozin, dkk (2019) This research has presented the using the educational game application to increase the learning result of the students in mathematics for sixth graders of elementary school students. This research found that: (1) Students: confidence and learning outcome of mathematics has improved. Therefore, it needs to be maintained for the improvement of student quality... Hal ini menunjukan bahwa dalam penerapan games, mampu meningkatkan hasil belajar dan kepercayaan diri siswa SD. oleh karena itu, melalui penerapan games tersebut, pada dasarnya mampu untuk diungkapkan secara nyata tentang kelebihan yang telah terwujud di tingkat SD.

Penelitian lain oleh Yudha, C.B (2018) media menggunakan game edukasi berbasis android lebih efektif dibandingkan media gambar. Jenis penelitian yang dilaksanakan adalah eksperimental dengan desain Randomized Pretest-Posttest Control Group Design. Dalam proses eksperimen dilakukan pengamatan pada tiga kelompok pembelajaran yaitu kelompok eksperimen satu yang diberi treatment dengan game edukasi berbasis Android, kelompok eksperimen dua dengan media gambar, dan kelompok kontrol dengan tanpa media. Hal ini artinya bahwa, penerapan games ini lebih efektif dari pada penggunaan gambar.

Pada SD Negeri Cibitung Kulon 01 Pagi Guru berperan sebagai pusat pembelajaran sehingga siswa kurang terlibat secara aktif selama pembelajaran. Kondisi ini menjadikan pembelajaran matematika kurang menarik di mata siswa dan akibatnya siswa kurang bersemangat selama proses pembelajaran. kondisi yang terjadi di SD Negeri Cibitung Kulon belum sesuai dengan pengertian guru menurut Undang-Undang RI No 14 
Tahun 2005 yaitu guru adalah pendidik profesional dengan tugas utama mendidik, mengajar, membimbing, mengarahkan, melatih, menilai, dan mengevaluasi peserta didik pada pendidikan anak usia dini jalur pendidikan formal, pendidikan dasar, dan pendidikan menengah.

Berdasarkan hasil pengamatan di SD Negeri Cibitung Kulon 01 Pagi maka permasalahan yang mendesak untuk di selesaikan adalah bagaimana metode atau cara penerapan fun math/permainan puzzle tetris matematika kepada para guru di SDN Cibitung Kulon 01 Pagi. Sehingga tujuan diselenggarakannya kegiatan pengabdian adalah meningkatkan pemahaman dan kemampuan guru-guru SDN Cibitung Kulon 01 Pagi tentang pembelajaran matematika yang menyenangkan.

\section{Metode Pelaksanaan}

Rancangan prosedur kegiatan program PKM yang diusulkan meliputi tahapan: (1) persiapan, (2) pelaksanaan, (3) observasi dan evaluasi, (4) penulisan laporan. Adapun subjek pengabdian ini adalah seluruh guru-guru SDN Cibitung Kulon 01 Pagi yang berjumlah 15 orang. Selanjutnya, instrumen dalam kegiatan pengabdian masyarakat ini yaitu lembar observasi sedangkan teknik pengumpulan data melalui observasi yang digunakan untuk mengamati semua aktivitas peserta selama kegiatan sosialisasi berlangsung. Data-data yang telah diperoleh tersebut, kemudian akan diolah dan disajikan dalam bentuk deskriptif. Pelaksanaan program ini ditujukan untuk guru-guru SDN Cibitung Kulon 01 Pagi.

Pada pelaksanaannya terdapat langkah-langkah yang dilaksanakan, yaitu melalui pengelompokan sebanyak 2 guru setiap kelompoknya. Saat pelaksanaan diskusi kelompok berlangsung tersebut melalui petunjuk penggunaan tetris math. dijabarkan sebagai berikut:

a. Untuk memulainya, anda harus menemukan kepingan puzzle tetmath yang memiliki nomor 1, 2, dan 3 kemudian pasangkan sesuai dengan pola yang benar (puzzle tetmath memiliki pola untuk setiap pasang kepingan yaitu pola S, J, dan C) jika sudah menemukannya lalu posisikan kepingan-kepingan tersebut di pojok kiri atas.

b. S, J, dan C merupakan simbol untuk: S adalah soal, J adalah jawaban, dan $\mathrm{C}$ adalah contoh. Setiap kepingan memiliki simbol-simbol ini sesuai dengan isi yang berada di badan kepingan, apakah kepinag tersebut merupakan soal, jawaban, atau contoh, sesuaikan. *lihat gambar pada bag. 2

c. Menyesuaikan kepingan S, J, dan C haruslah tepat dan benar yaitu dengan menemukan kepingan bersimbol $S$ (soal) terlebih dahulu kemudian anda mencari pasangannya yaitu kepingan $\mathrm{J}$ (jawaban) dan $\mathrm{C}$ (contoh) sesuai dengan soal yang dimiliki pada badan kepingan S (soal). Di sini pengetahuan mengenai materi bangun datar (persegi, persegi panjang, dan segitiga) sangat diperlukan agar dapat menyelesaikan puzzle tetmath ini.

d. Jika sudah menemukan S, J, dan C yang tepat dan benar seuai dengan polanya, susun kepingan lain dengan cara yang sama yaitu menemukan kepingan S (soal) terlebih dahulu baru kemudian pasangkan dengan kepingan $\mathrm{J}$ (jawaban) dan $\mathrm{C}$ (contoh) yang sesuai dengan kepingan $\mathrm{S}$ 
(soal)nya, lakukan hingga kepingan habis. *pola puzzle tetmath dapat dilihat sesekali jika anak mengalami kesulitan memasangkan kepingannya

e. Kepingan tersusun rapi dan pas. Sesuaikan bentuk antar kepingan saat memasangkannya, tidak dengan cara dipaksakan.

Kepingan hitam merupakan tanda bahwa anda telah berhasil memecahkan puzzle tetmath, kepingan tersebut harus dipasangkan setelah semua kepingan habis dipasangkan dan tidak ada yang tersisa. Selanjutnya, proses evaluasi dilaksanakan untuk mengetahui kekurangan dan kendala dalam pelaksanaan kegiatan sehingga dapat dilakukan penyempurnaan. Proses evaluasi dilakukan melalui kegiatan wawancara kepada peserta secara langsung mengenai kegiatan penyuluhan dan sosialisasi.

\section{Hasil dan Pembahasan}

Berdasarkan evaluasi dalam pelaksanaan program sosialisasi dan penyuluhan ini ternyata diperoleh hasil bahwa peserta yang hadir dalam program ini ternyata sudah bisa dikatakan memenuhi target yaitu sebanyak 15 orang peserta yang datang dari 17 orang peserta yang ditargetkan. Selain itu seluruh peserta yang datang juga telah mewakili kelas yang ada di SDN Cibitung Kulon 01 Pagi Kegiatan sosialisasi ini telah berjalan dengan lancar dan sesuai dengan yang diharapkan, namun untuk jadwal pelaksanaannya agak mundur dari jadwal yang telah disusun yang mana seharusnya kegiatan dimulai pada pukul 08.00 WIB namun baru terlaksana pada pukul 09.00 WIB, hampir seluruh guru selaku peserta kegiatan sosialisasi dan pengabdian ini mengikuti seluruh rangkaian acara dari awal sampai akhir kegiatan yaitu pukul 12.30 WIB. Selain itu, para peserta juga terlihat antusias mendengarkan/memperhatikan pemaparan materi dari para pemateri dan juga adanya interaksi diskusi dan tanya jawab yang terjadi pada sesi tanya jawab merupakan salah indikator atau daya tarik tersendiri dari peserta terhadap materi yang disampaikan oleh para pemateri.

Table 1. Hasil Evaluasi Pemahaman matematika Dasar dengan Fun Math

\begin{tabular}{ccc}
\hline Kategori & $\%$ & Total \\
\hline Kategori Tinggi & 8 & 58,9 \\
Kategori Sedang & 5 & 30,8 \\
Kategori Rendah & 2 & 10,3 \\
\hline
\end{tabular}

Kategori ini digunakan untuk mengetahui pemahaman guru terhadap materi yang telah disampaikan dan mengukur seberapa pesen berhasilnya kegiatan PKM yang telah dilakukan. Berdasarkan tabel diatas dapat dijelaskan bahwa dari jumlah peserta yang hadir sebanyak 15 orang, 8 orang guru memhami materi dengan sangat baik atau dalam kategori tinggi, sedangkan 5 orang guru memahami maeri dengan baik dan hanya 2 orang guru yang kurang memahami materi yang telah dijelaskan. Hasil evalusai ini menjadi tolak ukur bahwa tujuan PKM tercapai. Evaluasi yang telah diberikan kepada guru berbentuk soal uraian sebanyak 25 soal terkait materi yang telah disampaikan. 


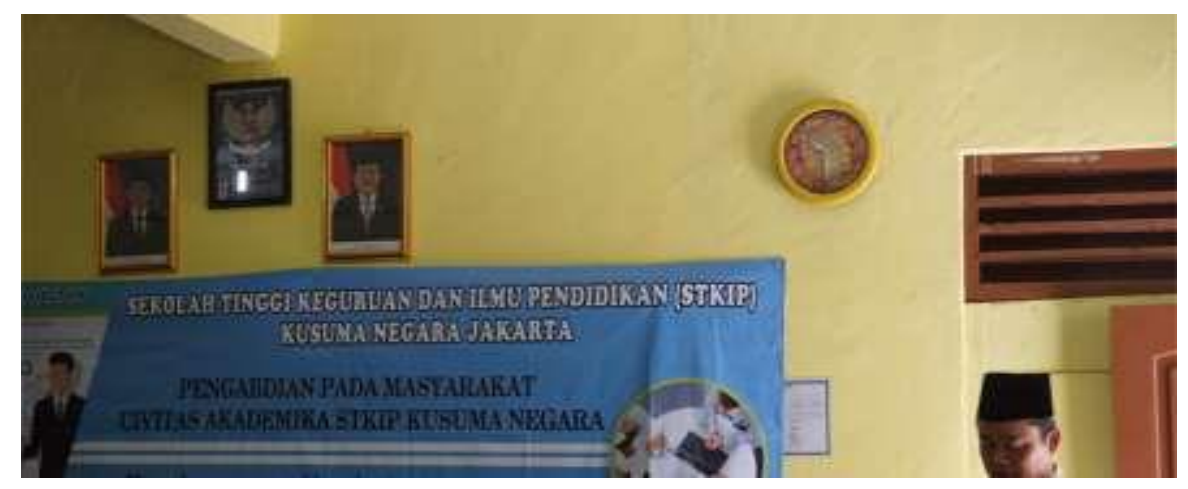

Gambar 1. Banner Kegiatan PKM

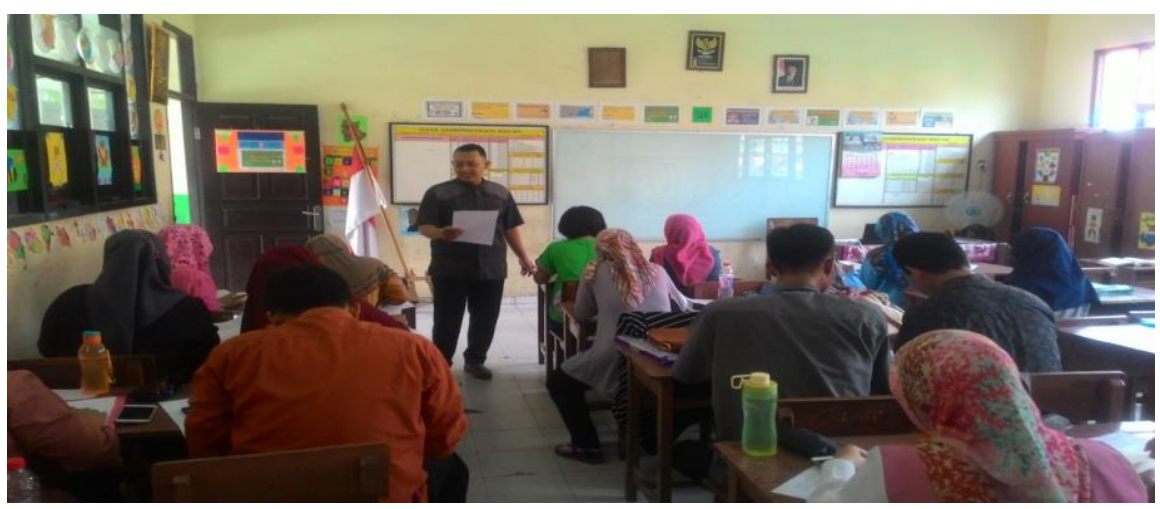

Gambar 2. Pematerisedangmemaparkan materi $P K M$

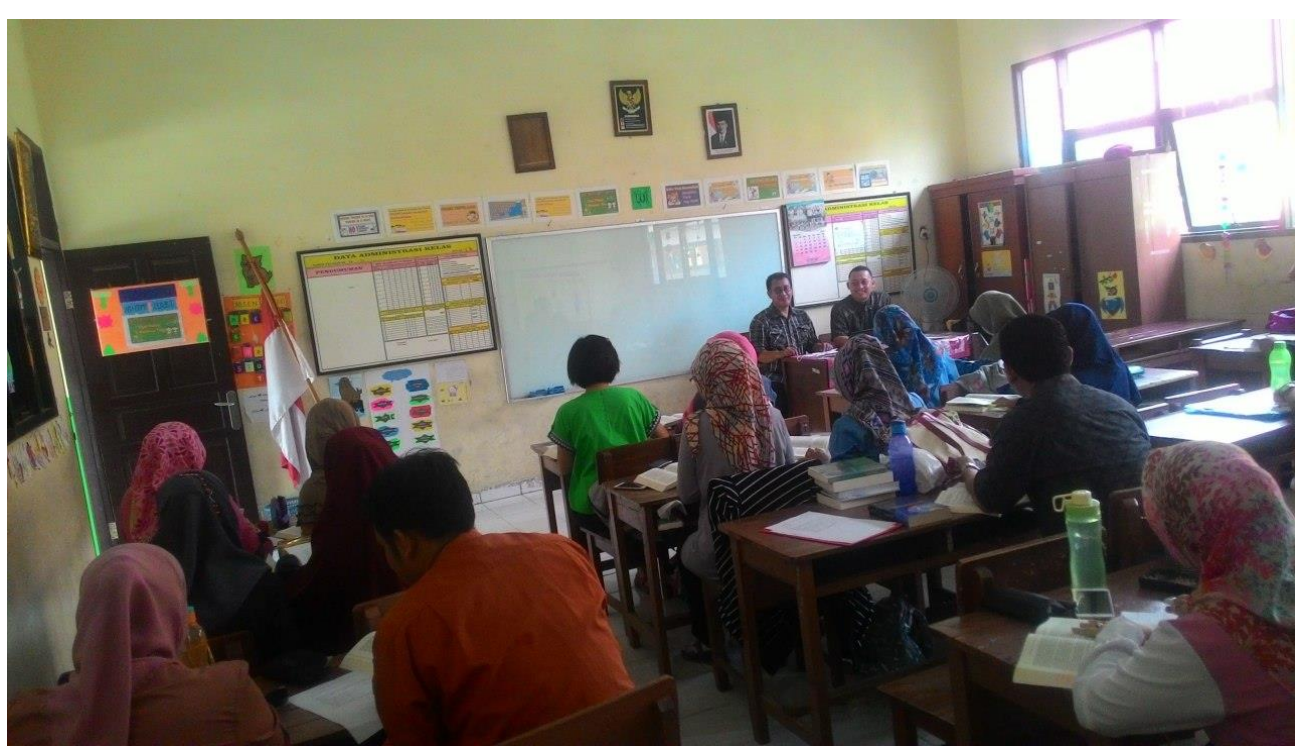

Gambar 3. Sesi Diskusidengan Peserta PKM

\section{Simpulan dan Tindak Lanjut}

Kesimpulan yang dapat diperoleh dari pelaksanaan program pengabdian kepada masyarakat ini adalah: kegiatan sosialisasi ini dapat meningkatkan pengetahuan guru-guru mengenai cara menciptakan 
pembelajaran matematika yang menyenangkan di kelas. Selanjutnya, pelaksanaan dari program kegiatan pengabdian pada masyarakat ini sudah berjalan dengan lancar dan sesuai dengan yang diharapkan, baik oleh anggota tim penyuluhan maupun para peserta program pengabdian masyarakat. Setelah kegiatan ini terlaksana dengan baik, maka ada beberapa saran yang dapat disampaikan kepada beberapa pihak, antara lain yaitu: (1) Kepada tim pengabdi program pengabdian masyarakat selanjutnya diharapkan agar dapat menyajikan materi yang lebih luas dan dapat merangkul peserta yang lebih banyak agar tujuan dan manfaat dari pelaksanaan program ini dapat terlaksana secara berjenjang, bertahap dan berkelanjutan; (2) Kepada kepala sekolah agar dapat menjadikan program kegiatan sosialisasi dan penyuluhan ini atau yang sejenisnya sebagai salah satu agenda rutin yang dapat diselenggarakan pada setiap tahunnya dengan mengadakan kerjasama atau melibatkan dinas atau universitas atau lembaga yang lain; (3) Kepada guru- guru agar dapat mengaplikasikan/menyampaikan materi kegiatan sosialisasi dan penyuluhan ini dalam proses pembelajaran matematika.

\section{Daftar Pustaka}

Dewi, N.R., Yuliza, E., Eliati, N. \& Faruk, A. 2019. Pendampingan Merancang Penelitian Tindakan Kelas Dan Penulisan Publikasi Kepada Guru-Guru SD di Desa Sakatiga. Jurnal Pemberdayaan: Publikasi Hasil Pengabdian kepada Masyarakat Vol. 3, No. 3, Hal. 367-372. DOI: https://doi.org/10.12928/jp.v3i1.1270

Ahmad dan Amini. 2020. Kemampuan Kognitif dalam Mengurutkan Angka melalui Metode Bermain Puzzle Angka. Jurnal Obsesi : Jurnal Pendidikan Anak Usia Dini, 4(1), 2020

Atiaturrahmaniah, dkk. Pengembangan Pendidikan Matematika SD, (Lombok: Universitas Hamzanwadi Press, 2017), hlm. 16.

Farozin, M., Yudha, C. B., Herzamzam, D. A., \& Sicad, M. (2019). The Educational Games Application Using Smartphone in Learning Mathematics for Elementary School Students. International Journal of Advanced Science and Technology, 122, 1-14.

Karso, dkk. Pendidikan Matematika I, (Tangerang Selatan: Universitas Terbuka, 2014), hlm. 1.17.

Kemdikbud. (2018). Senang Belajar Matematika SD/MI Kelas IV. Jakarta: Kemdikbud

Mahardika, Asrori.M, Desni Yuniarni. 2013. Permainan Edukatif Dengan Media Puzzle Mengembangkan Kemampuan Kognitif Anak Usia 4 - 5 Tahun Tk Islamiyah. Jurnal Untan. http://jurnal.untan.ac.id/index.php/jpdpb/article/download/3631/3 640

$\begin{array}{lllll}\text { Nick } & \text { Parlante, } & \text { Lab } & 9 & \text { Tetris. }\end{array}$ http: / / www.bowdoin.edu/ echown/courses/210/javalab9/TetrisAssig nment.pdf diakses tanggal 25 Februari 2020 pukul 17.00

Ratu Risky Aifah*, Chrisnaji Banindra Yudha, Eva Oktaviana.2020.Pengembangan Media Permainan Puzzle Tetris 
Mathematics pada Materi Bangun Datar. Prosiding Seminar Nasional Pendidikan STKIP Kusuma Negara II, 51-58.

Wiwi Alawiyah, Yusuf Suryana, Oyon Haki Pranata. 2019. Pengaruh Media Puzzle terhadap Hasil Belajar Siswa tentang Bangun Datar Di Sekolah DasarJurnal Ilmiah Pendidikan Guru Sekolah Dasar - Vol. 6, No. 1 (2019) 118-129

Yudha, C.B,. \& Suwarjo, S. (2014). Peningkatan Kepercayaan Diri dan Proses Belajar Matematika Menggunakan Pendekatan Realistik Pada Siswa Sekolah Dasar. Jurnal Prima Edukasia, 2(1), 42-56. https: / /journal.uny.ac.id/index.php/jpe/article/view/2643/2198

Yudha, C.B (2018) Penerapan Game Edukasi Berbasis Android dan Gambar Bagi Siswa Sekolah Dasar. Jurnal Tunas Bangsa Vol. 5, No.2, Agustus 2018

Priatna, Nanang. Yuliardi, R. (2018). Pembelajaran Matematika untuk Guru $S D$ dan Calon Guru SD. Bandung: PT Remaja Rosdakarya.

Undang-Undang Republik Indonesia Nomor 14 Tahun 2005 Tentang Guru dan Dosen https://jdih.kemenkeu.go.id/fulltext/2005/14tahun2005uu.html 